\section{AB1414-HPR LONG TERM EFFECTIVENESS OF A TREAT TO TARGET APPROACH AND IMPACT IN OVERALL HEALTH IN PATIENTS WITH RHEUMATOID ARTHRITIS - A 3 YEAR FOLLOW-UP}

D Buitrago-Garcia ${ }^{1}$, L. Villarreal ${ }^{2}$, M. Cabrera ${ }^{2}$, P. Santos-Moreno ${ }^{3} .{ }^{1}$ Epidemiology, $^{2}$ SIIES; ${ }^{2}$ Health services; ${ }^{3}$ Rheumatology, Biomab, Center For Rheumatoid Arthritis, Bogota, Bogota, Colombia

Background: Rheumatoid arthritis (RA) is a common chronic inflammatory disease. It is characterised by progressive, irreversible joint damage, impaired joint function and pain, the disease causes disability and reduced quality of life. Treat-to-target (T2T) is an acknowledged management strategy for RA. It proposes that the therapeutic target in RA should be a state of remission, or an alternative goal could be a low disease activity, additionally it looks to achieve long-term health quality of life for the patient. ${ }^{1,2}$

Objectives: To describe the effectiveness of a T2T strategy regarding Disease Activity Score 28 (DAS28) in a 36 month period in patients who receive conventional or biological DMARDs and attend at least at four consults per year in a specialised in RA centre.

Methods: A descriptive cohort study was conducted. Medical records of patients from specialised in RA centre were reviewed between 20152017; those patients were followed-up under T2T standards and a multidisciplinary approach. Each patient had a minimum of 4 follow-up visits per year. Clinical follow-up was designed by the authors according to DAS28 as follows: every $3-5$ weeks (DAS28 >5.1), every $7-9$ weeks (DAS28 $\geq 3.1$ and $\leq 5.1$ ), and every $11-13$ weeks (DAS28 $<3.1$ ). Therapy had to be adjusted with DAS28 $>3.2$ unless patient's conditions don't permit it; We divided patients in four groups: remission (REM), low disease activity (LDA), moderate disease activity (MDA) and severe disease activity (SDA) patients and the aim of the study was to look at what percentage of patients reached a LDA or REM. Descriptive epidemiology was done, we calculated means, and standard deviations for continuous variables and categorical variables were presented as rates. We analysed normality for DAS28, in order to compare disease activity at beginning and the end of follow-up.

Results: During three years 1146 patients had confirmed RA and attended to a specialised centre with a minimum of 4 visits per year, $86 \%$ were female and $14 \%$ were men, mean DAS28 at baseline was $3.69 \pm 1.10$ with a median of 3.1 while at 3 years mean DAS28 was 2.94 \pm 0.87 with a median of 2.79 . At baseline $46 \%$ were in LDA, $40 \%$ in MDA and $13 \%$ were in SDA. Regarding pharmacological therapy $63 \%$ were receiving conventional DMARDs while $37 \%$ were receiving biological DMARDs. When we evaluated the effectiveness of T2T approach in terms of disease activity at the end of 36 months $42 \%$ achieved remission and $26 \%$ LDA (in total $68.5 \%$ of patients improved clinically) see table 1. We performed a Wilcoxon test in order to compare the mean DAS28 at baseline and at the end showing statistical significance $(\mathrm{p}<0.05)$.

Abstract AB1414-HPR - Table 1

\begin{tabular}{lcccc}
\hline ACTIVITY LEVEL & \multicolumn{2}{c}{ AT BASELINE } & \multicolumn{2}{c}{3 YEARS FOLLOW-UP } \\
\cline { 2 - 5 } & $\mathrm{n}$ & $\%$ & $\mathrm{n}$ & $\%$ \\
\hline REM & & & 488 & 42.6 \\
LDA & 532 & 46.42 & 297 & 25.9 \\
MDA & 462 & 40.31 & 336 & 29.3 \\
SDA & 152 & 13.26 & 25 & 2.2 \\
\hline
\end{tabular}

Conclusions: This real-world data demonstrates the effectiveness of a T2T multidisciplinary approach in patients with rheumatoid arthritis who remained in conventional or biological therapy during three years.

\section{REFERENCES:}

[1] Aletaha D, Alasti F, Smolen JS. Optimisation of a treat-to-target approach in rheumatoid arthritis: strategies for the 3-month time point. Annals of the Rheumatic Diseases. 2015.

[2] Cardiel MH. Treat to target strategy in rheumatoid arthritis: real benefits Reumatologia clinica. 2013;9(2):101-5.

Disclosure of Interest: None declared DOI: 10.1136/annrheumdis-2018-eular.6101

\section{AB1415-HPR DIFFERENCES ON PAIN AND STRUCTURAL ANORMALITIES BETWEEN PATIENTS WITH RHEUMATOID ARTHRITIS AND THOSE WITH INESPECIFIC FOOT PAIN: CROSS SECTIONAL STUDY}

G Gijon-Nogueron ${ }^{1}$, A. Reinoso-Cobo ${ }^{1}$, A.B. Ortega-Avila ${ }^{1}$, R. Caliz ${ }^{2} .{ }^{1}$ Nursing and Podiatry, University of Malaga, Malaga; ${ }^{2}$ Servicio de Reumatologia, Hospital Virgen de las Nieves, Granada, Spain

Background: The presence of foot pain and deformity is ubiquitous in Rheumatoid Arthritis (RA). Epidemiological studies consistently suggest a prevalence of foot pain of $90 \% .^{1}$ Weight gain, high levels of fatigue and deformities such us hallux valgus and metatarsus primus varus, are very frequent too. ${ }^{2}$

Objectives: The aim of this study was to analyse pain levels and structural anormalities among subjects with foot pain and patients with RA. Methods: A sample comprised of 40 subjects was studied. Participants were recruited from a private podiatry clinic and from the Department of Rheumatology (Granada, Spain). The inclusion criteria were subjects with RA with a duration of at least 10 years according to the American Rheumatism Association criteria for RA, while patients with foot pain seeking podiatry services from April 2017 to January 2018 were used as control group. Outcome measures were as follows: foot pain, activity limitation, disability and foot health status by Foot Function Index questionnaire ${ }^{3}$ and Hallux Valgus by Manchester Hallux Valgus Scale. ${ }^{4}$

Results: As shown in Table 1, we found statistical significant differences for the pain scale $(p>0.001)$ and in total $s c o r e(p>0.001)$ in the FFI scale between AR group and the control group, but not between group in the Manchester Hallux Scale $(p=0.986)$

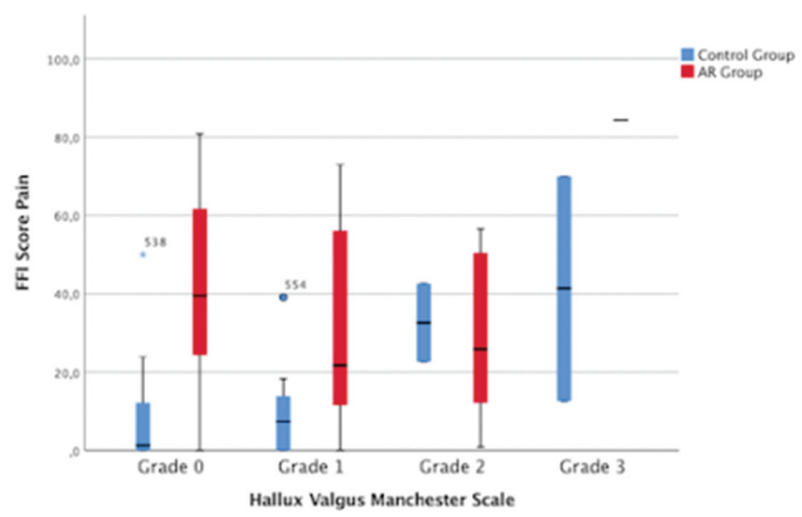

Abstract AB1415-HPR - Figure 1

Conclusions: We found higher levels of pain in subjects with RA compared to the control group. Furthermore, although there are clinical

Abstract AB1415-HPR - Table 1

\begin{tabular}{|c|c|c|c|c|c|c|c|c|c|}
\hline \multirow[b]{2}{*}{ Age(years) } & \multirow{2}{*}{$\begin{array}{l}\text { Mean } \\
53.8\end{array}$} & \multirow{2}{*}{$\begin{array}{c}\text { SD } \\
\text { Control Group } \\
13.3\end{array}$} & \multicolumn{2}{|c|}{$\mathrm{Cl} 95 \%$} & \multirow{2}{*}{$\begin{array}{l}\text { Mean } \\
56.78\end{array}$} & \multicolumn{2}{|c|}{$\begin{array}{l}\text { SD } \\
\text { Rheumatoid Arthritis Group }\end{array}$} & Cl $95 \%$ & \multirow{2}{*}{$\frac{p \text { values }}{0689}$} \\
\hline & & & 49.55 & 58.05 & & 14.86 & 51.83 & 61.74 & \\
\hline BMI(Kg/m2) & 26.9 & 3.87 & 28.48 & 25.49 & 27.1 & 2.46 & 28.74 & 25.33 & 0.879 \\
\hline FFI TOTAL & 11.08 & 15.57 & 6.1 & 16.05 & 39.03 & 26.44 & 30.21 & 47.85 & $>0, .001$ \\
\hline FFI Pain & 14.75 & 18.8 & 8.71 & 20.79 & 41.16 & 22.54 & 33.65 & 48.68 & $>0, .001$ \\
\hline Manchester & 52.5 & 35 & 10 & 2.5 & 54.1 & 32.4 & 10.8 & 2.7 & 0.986 \\
\hline $\begin{array}{l}\text { Hallux Scale } \\
\%\end{array}$ & None & Mild & Moderate & Severe & None & Mild & Moderate & Severe & \\
\hline
\end{tabular}

